\title{
A Six Year Review of Odontoid Fractures: The Emerging Role of Surgical Intervention
}

\author{
Wendy C. Ziai and R. John Hurlbert
}

\begin{abstract}
Background: Traditionally, odontoid fractures have been treated with different bracing techniques resulting in variable degrees of successful healing. Surgical intervention is becoming more widely practiced as a primary intervention. The purpose of this report was to survey our recent experience in southern Alberta to determine potential outcome differences in management strategies. Methods: We retrospectively reviewed the charts of 520 patients diagnosed with cervical spine fractures over a six-year period from January 1990, through December 1996. Patients were identified through the medical records database of the two Level 1 trauma facilities, on the basis of ICD-9 diagnostic coding. Results: Ninety-three fractures of the odontoid process were identified, of which 85 were acute and eight were chronic. There were 57 Type II (67\%) and 27 Type III (32\%) acute odontoid fractures. Of these, 64 were managed conservatively (bracing), whereas 20 were treated surgically. Thirteen patients underwent anterior screw fixation, seven patients had posterior cervical fusion. Eleven patients died in the acute phase, two as a result of their high cervical cord injury and nine from unrelated medical causes. Fifty-six of the remaining 82 patients $(68 \%)$ were located with a minimum of three months follow-up (range three months to eight years). Satisfactory results were obtained in $76 \%$ of all acute patients treated by bracing, but only $50 \%$ in those over the age of 65 . In the surgically managed group, all patients (100\%) went on to develop stable fusions. Conclusions: Our results indicate that while conservative management of odontoid fractures with external bracing results in fracture healing in most cases, surgical fusion may provide superior rates of bony union with acceptable morbidity. This difference in outcome lends itself to formal investigation through a prospective randomized trial.
\end{abstract}

RÉSUMÉ: Revue des cas de fractures de l'apophyse odontoïde sur une période de six ans: le rôle de la chirurgie. Introduction: Traditionnellement, les fractures de l'apophyse odontoïde ont été traitées par différentes techniques de orthésiques produisant des résultats variables. On a recours de plus en plus à la chirurgie comme traitement initial. Le but de cet article était d'évaluer notre expérience récente dans le sud de l'Alberta pour déterminer s'il existait des différences de résultats selon les stratégies de traitement. Méthodes: Nous avons révisé rétrospectivement sur une période de six ans, de janvier 1990 à décembre 1996, les dossiers de 520 patients ayant un diagnostic de fracture de la colonne cervicale. Les patients étaient identifiés par le diagnostic codifié conformément à la CIM-9 dans leur dossier médical contenu dans une base de données dans les deux centres de traumatologie de niveau 1. Résultats: 93 fractures de l'apophyse odontoïde ont été identifiées, dont 85 étaient aigues et 8 chroniques. Il y avait 57 fractures aiguës de type II (67\%) et 27 de type III (32\%). 64 patients ont reçu un traitement conservateur (orthèse) alors que 20 ont subi une chirurgie. 13 patients ont subi une fixation au moyen d'une vis antérieure et 7 ont subi une fusion cervicale postérieure. Onze patients sont décédés en phase aiguë, deux suite à un traumatisme haut de la moelle épinière et neuf de causes médicales non reliées. Le suivi chez 56 des 82 autres patients (68\%) était d'au moins trois mois (de trois mois à huit ans). Un résultat satisfaisant a été obtenu chez $76 \%$ de tous les cas aigus traités par orthèse, mais seulement chez $50 \%$ des patients âgés de plus de 65 ans. Dans le groupe qui a subi une chirurgie, tous les patients (100\%) ont éventuellement développé une fusion stable. Conclusions: Nos résultats indiquent que, bien que le traitement conservateur par orthèse externe entraine la guérison de la plupart des fractures de l'apophyse odontoïde, la fusion chirurgicale donne des taux supérieurs d'union osseuse et une morbidité acceptable. Cette différence dans les résultats peut servir de base à une investigation formelle au moyen d'un essai randomisé.

Can. J. Neurol. Sci. 2000; 27: 297-301

Odontoid fractures account for approximately 11 percent of cervical spine traumatic injuries. ${ }^{1,2,3}$ The management of these fractures remains controversial and a variety of stabilization techniques have been employed with varying success rates. Recently, new surgical techniques have allowed operative intervention to take on the role of a primary treatment alternative, often preserving motion through the atlanto-axial complex. ${ }^{4,5}$ Following the introduction of these techniques into our surgical practice, we undertook to review our experience and the outcomes of our patients during this transition period.
Ninety-three odontoid fractures treated between 1990 and 1996 were identified. The results of long-term immobilization versus surgical intervention are retrospectively compared.

\footnotetext{
From theUniversity of Calgary Spine Program, and the Department of Clinical Neurosciences, University of Calgary, Calgary, Alberta, Canada. ReCEIVED JANuARY 25, 2000. ACCEPTED INFINALFORM JunE 20, 2000. Reprint requests to: R. John Hurlbert, University of Calgary Spine Program, Foothills Hospital and Medical Clinic, 1403 - 29th St. N.W., Calgary, AB, T2N 2T9 Canada.
} 


\section{Methods}

Five hundred and twenty cervical spine fractures were treated at the Foothills Hospital and Medical Centre and the Calgary General Hospital between January 1990 and December 1996. Individual chart review was performed on these patients to identify those diagnosed with odontoid fractures. Subsequently, further detailed review was undertaken to obtain information on: age, sex, cause of injury, degree of displacement of the fracture, neurological symptoms and status, the presence of complicating injuries and other spinal fractures, fracture treatment and followup, duration of hospitalization, and management of treatment failures. The diagnosis of odontoid fracture was based on anterior/posterior (AP) and lateral cervical, and open mouth odontoid radiographs. Standard tomograms and/or computed tomography (CT) of the cervical spine were performed for further clarification or where the diagnosis was in doubt. Magnetic resonance imaging was not routinely performed. Acute fractures were defined as those diagnosed within 10 days of the traumatic event, while subacute/chronic fractures were defined as those diagnosed later than 10 days.

Fifty-six of 82 surviving patients $(68 \%)$ were available for a minimum of three months follow-up. This consisted of review of physician outpatient records, direct patient reassessment where possible, telephone interviews, and follow-up flexion-extension radiographs. The median follow-up duration was six months with a range of three months to eight years. Fracture stability was determined based upon flexion-extension X-rays for all except 12 patients who met criteria for bony union on static radiographs (loss of cortical margins, graft incorporation, callus formation). Nonunion was defined by the presence of radiolucency on plain radiographs, observable movement in flexion and extension, or hardware failure.

\section{RESUlTS}

Ninety-three patients were diagnosed with odontoid fractures within the review period. There were 58 male and 35 female patients, with a mean age of 57 (range 16-94 years). Eighty-five acute odontoid fractures were identified including Type $I(n=1)$, Type II $(n=57)$, and Type III $(n=27)$ injuries. The Type I fracture occurred in a patient with rheumatoid arthritis and required no further treatment. Rheumatoid arthritis was not a risk factor in any other patient. Of eight chronic fractures, there were five Type II and three Type III injuries. Eleven deaths occurred within the first six weeks of injury. Two patients died as a direct result of the cervical cord injury. Seven patients died from respiratory compromise unrelated to the odontoid fracture and two patients died of other medical illnesses. Of the 85 patients with acute injuries, 81 were medically fit to undergo treatment (four patients were either moribund or died prior to intervention).

The causes of traumatic injury are summarized in Table 1. In the $16-34$ age group $(n=19)$ the most common mechanism of injury was motor vehicle accidents, while in the 65-94 age group $(n=33)$ falls were most prevalent. Symptomatically, 66 patients presented with cervical pain, eight complained of paresthesias, and five noted specific motor weakness or paralysis. On initial assessment, 78 patients (84\%) were neurologically intact. Two patients were quadriplegic as a result of the odontoid fracture, and 10 patients suffered partial spinal cord injuries. Three patients had uncertain fracture-related neurological deficits due to associated severe head injury. Fifteen patients $(16 \%)$ had associated significant head injury, 18 patients (19\%) had other acute cervical spine fractures, and six patients $(6 \%)$ had acute thoracic or lumbar spine fractures.

In fourteen patients $(15 \%)$ a delay in diagnosis ranging from one day to four months was documented. Odontoid fracture was unrecognized on initial cervical radiographs by the attending physician in four cases; two patients were diagnosed after transfer from a peripheral center where adequate imaging (CT scan) could not be performed; four patients did not seek immediate medical attention; and a cervical spine radiograph was not performed by the admitting community hospital in two instances. These delays in diagnosis did not adversely affect the neurological status of any patient.

Cervical spine radiographs were analyzed for the degree of anterior or posterior subluxation of the odontoid peg with respect to the body of $\mathrm{C} 2$, in $\mathrm{mm}$. The relationship between degree of displacement on admission to neurological deficit is shown in Table 2. The degree of dislocation ranged from 2 - $11 \mathrm{~mm}$ of displacement. Posterior subluxation accounted for the largest patient group and was most commonly associated with neurological deficit. The two complete cord injuries both occurred in patients with posterior displacement. No patient with a chronic fracture had a neurological deficit despite presence of subluxation in four cases.

\section{External immobilization}

Sixty-nine fractures were treated with a course of external skeletal fixation, 13 of which underwent initial fracture reduction with skeletal tong traction. Traction was employed for seven of the 10 partial spinal cord injuries, one $\mathrm{C} 2$ root injury and five intact patients; seven of the 13 patients placed in traction had displacement of greater than $4 \mathrm{~mm}$. Table 3 demonstrates the types of external fixation devices used for each fracture type in the conservatively treated group. Halo fixation was the preferred method for both Type II and III fractures. Hard collars were the second most frequently used device. External fixation was applied for a period ranging from two to four months depending on fracture characteristics and surgeon preference. Treatment in a soft collar $(n=2)$ was reserved for elderly patients whose medical or mental status would not permit rigid immobilization.

Fractures treated with external immobilization were reassessed for fracture healing with AP and lateral cervical spine radiographs. Forty-five of 64 acute patients $(70 \%)$ were available for a minimum three-month follow-up. Four patients died before fracture healing could be assessed and fifteen patients were lost to follow-up. The overall result of external immobilization in acute patients was a solid union in 34 (76\%) and nonunion in 13 patients $(24 \%)$ (Table 4$)$. The nonunion rate was substantially higher for Type II fractures $(30 \%)$ compared to Type III injuries (17\%).

In all patients treated with external immobilization, the nonunion rate observed for posterior subluxation was $38 \%$, for anterior subluxation $14 \%$, and for nondisplaced fractures $25 \%$ (Table 5). The two patients with anterior subluxation and nonunion had displacements of 3 and $5 \mathrm{~mm}$, well within the range of 3 to $6 \mathrm{~mm}$ anterior displacement in their counterparts who fused. Similarly, in the posteriorly displaced group there was no apparent correlation between the degree of subluxation 
Table 1: Mechanism of Injury in 93 patients

\begin{tabular}{lccc}
\hline Patient Age (yr) & MVA & Fall & Other \\
$16-34$ & 19 & 2 & 2 \\
$35-49$ & 5 & 6 & 3 \\
$50-64$ & 6 & 4 & 0 \\
$65-94$ & 11 & 33 & 2 \\
Total & 41 & 45 & 7
\end{tabular}

"Other" includes motorcycle accidents

Table 2: Initial Neurological Status Related to Degree of Fracture Subluxation

\begin{tabular}{lcccc}
\hline Neurologic Status & \multicolumn{3}{c}{$\begin{array}{c}\text { Presence/Direction of Fracture Subluxation } \\
\text { (no. of patients) }\end{array}$} \\
& None & Anterior & Posterior & Other \\
Complete SCI & 0 & 0 & 2 & 0 \\
Partial SCI & 0 & 3 & 7 & 0 \\
No Deficit & 32 & 19 & 26 & 1 \\
Uncertain & 1 & 0 & 2 & 0 \\
Total & 33 & 22 & 37 & 1 \\
\hline
\end{tabular}

"Other" denotes one patient with lateral shift of odontoid peg relative to body of $\mathrm{C} 2$

"SCI" denotes spinal cord injury

Table 3: Type of External Fixation Device Used Related to Fracture Type (68 patients)

\begin{tabular}{lcccc}
\hline & \multicolumn{2}{c}{$\begin{array}{c}\text { No. of Patients with } \\
\text { Acute Injuries }\end{array}$} & \multicolumn{2}{c}{$\begin{array}{c}\text { No. of Patients with } \\
\text { Chronic Injuries }\end{array}$} \\
Fixation Device & Type II & Type III & Type II & Type III \\
Halo Vest & 17 & 12 & 0 & 0 \\
Hard Collar & 13 & 6 & 1 & 2 \\
Somi Brace & 5 & 6 & 0 & 0 \\
Guilford Brace & 2 & 2 & 0 & 0 \\
Soft Collar & 1 & 0 & 0 & 1 \\
Total & 38 & 26 & 1 & 3 \\
& & & & \\
\hline
\end{tabular}

Table 4: Outcome in Patients with External Fixation Related to Fracture Type

\begin{tabular}{lcccc}
\hline & \multicolumn{2}{c}{ Acute Injuries } & \multicolumn{2}{c}{ Subacute/Chronic Injuries } \\
Result & Type II & Type III & Type II & Type III \\
Union & 19 & 15 & 0 & 1 \\
Nonunion & 8 & 3 & 0 & 1 \\
Lost to F/U & 7 & 8 & 1 & 1 \\
Dead & 4 & 0 & 0 & 0 \\
Total & 38 & 26 & 1 & 3 \\
& & & & \\
\hline
\end{tabular}

F/U : follow-up and the rate of nonunion; displacement in six patients with nonunion ranged from 1 to $8 \mathrm{~mm}$, while displacement in 10 patients who went on to fusion ranged from 2 to $8 \mathrm{~mm}$. The results of external fixation were also compared to age (Table 6). Patients in the youngest age group had a much lower rate of nonunion (17\%) compared to the oldest age group (50\%). The middle age groups also demonstrated low to intermediate nonunion rates increasing with advancing age (11\% 35-49 years and 25\% 50-64 years).

Within the conservatively treated group, a variety of external fixation devices were used. A comparison of method of external immobilization with outcome of treatment demonstrates that most patients were immobilized in a halo vest, achieving a radiographically solid fusion in $76 \%$ (Table 7). Although the numbers are small, $31 \%$ of patients (4/13) treated with a hard collar alone (Plastizote or Aspen collar) failed to fuse, suggesting halo bracing to be advantageous ( $24 \%$ nonunion). Only one of six patients treated with a Somi brace developed nonunion $(17 \%)$. Two of three patients treated with a Guilford brace failed to fuse. The two patients treated with soft collars were lost to follow-up and are not included in the analysis.

Thirteen patients in the conservative group (acute and

Table 5: Comparison of Direction of Subluxation with Treatment Outcome for All Nonsurgical Patients

\begin{tabular}{lcccc}
\hline Result & Ant. Sublux. & Post. Sublux. & No Displ. & Other \\
Union & 12 & 10 & 12 & 0 \\
Non Union & 2 & 6 & 4 & 1 \\
Lost to F/U & 5 & 5 & 7 & 0 \\
Dead & 1 & 1 & 2 & 0 \\
Total & 20 & 22 & 25 & 1 \\
& & & & \\
\hline
\end{tabular}

F/U: follow-up

Table 6: Comparison of Patient Age with Treatment Outcome for All Nonsurgical Patients

\begin{tabular}{lcccc}
\hline Patient Age (yr) & Union & Nonunion & Lost to F/U & Dead \\
$16-34$ & 15 & 3 & 3 & 0 \\
$35-49$ & 8 & 1 & 1 & 0 \\
$50-64$ & 3 & 1 & 2 & 0 \\
$65-94$ & 8 & 8 & 11 & 4 \\
Total & 34 & 13 & 17 & 4 \\
\hline
\end{tabular}

F/U:follow-up

Table 7: Comparison of Fixation Device with Treatment Outcome for All Nonsurgical Patients

\begin{tabular}{lcccc}
\hline Fixation Device & Union & Nonunion & Lost to F/U & Dead \\
Halo Brace & 19 & 6 & 4 & 0 \\
Other & 15 & 7 & 13 & 4 \\
Total & 34 & 13 & 17 & 4
\end{tabular}

F/U: follow-up 
Table 8: Results of Surgical Fusion in 18 Acute Odontoid Fractures

\begin{tabular}{lcc}
\hline Outcome & Anterior Screw Fixation & Posterior Cervical Fusion \\
Union & 5 & 4 \\
Nonunion & - & - \\
Lost to F/U & 7 & 1 \\
Dead & 1 & 2 \\
Total & 13 & 7 \\
\hline
\end{tabular}

F/U: follow-up

Table 9: Comparison of Patient Age and Management

\begin{tabular}{lccc}
\hline & \multicolumn{3}{c}{ Fracture Management: } \\
Patient Age (yr) & $\begin{array}{c}\text { External } \\
\text { Immob. }\end{array}$ & $\begin{array}{c}\text { Fixation } \\
\text { Fixation }\end{array}$ & $\begin{array}{c}\text { Posterior Cervical } \\
\text { Fusion }\end{array}$ \\
$16-34$ & 21 & 2 & 0 \\
$35-49$ & 10 & 1 & 2 \\
$50-64$ & 6 & 2 & 1 \\
$65-94$ & 31 & 8 & 4 \\
Total & 68 & 13 & 7 \\
\end{tabular}

chronic) developed nonunion following an adequate trial of external immobilization (28\%). Four patients were successfully fused through posterior cervical approaches (acute Type II $n=3$, chronic Type III $n=1$ ). One young patient was treated with anterior screw fixation after failing two weeks of halo immobilization due to loss of reduction. Four patients were managed with a longer duration of or even indefinite bracing, and four patients had no further management stated. It is not known whether patients treated for longer duration eventually achieved bony union although it is most likely that a fibrous nonunion was accepted in these elderly patients.

\section{Surgical stabilization}

Twenty patients underwent operative intervention as the primary form of treatment for reduction and stabilization of their fractures (acute $n=16$, subacute/chronic $n=4$ ). In the acute group, 11 patients with Type II injuries underwent anterior screw fixation, while four with Type II fractures and one with a Type III fracture were treated with posterior cervical fusion. In the subacute/chronic group, two patients with Type II fractures underwent anterior screw fixation while the other two underwent posterior cervical fusion. No Type III chronic fractures were initially treated with surgery.

The results of surgical fusion are shown in Table 8. As initial treatment, 13 anterior screw fixation procedures were carried out, 11 for acute fractures and two for chronic fractures. Each of five patients with minimum three month follow-up went on to develop stable fusions (100\%). One patient tore out the odontoid screws 24 hours after placement during an episode of acute respiratory distress requiring intubation. This patient was managed with replacement of a single screw on the right side and instructed to wear a collar at all times when upright. A solid bony union was confirmed radiographically after three months. Seven posterior cervical fusions (five for acute and two for chronic fractures) were performed. Only one patient was treated with post-operative halo immobilization; the others were treated with collars. Of the four patients with adequate follow-up, two acute injuries and one chronic fracture treated at five weeks achieved stable union. One patient with a chronic Type II fracture and 10 $\mathrm{mm}$ of initial posterior displacement suffered a loss of reduction following C1-C2 wiring without neurological deficit. This result was accepted without further management, leading to a solid arthrodesis. There were two deaths, both unrelated to surgery.

Surgical intervention was not biased towards a younger, potentially healthier population (Table 9). Eight surgical procedures were undertaken in patients under 65 years of age (18\%), whereas 12 procedures were performed in patients 65 years and older (29\%). The two postoperative complications (screw pull-out and loss of reduction) occurred in the oldest age group.

\section{Duration of hospitalization}

The average hospital stay for patients treated with external immobilization and an isolated odontoid fracture was 11 days. This compares with an average hospital stay of 10 days for patients treated surgically. There was no remarkable difference in length of stay for patients surgically treated with an anterior approach compared to a posterior approach.

\section{Discussion}

The results observed in this patient cohort support ongoing use of external immobilization for odontoid fractures with acceptable rates of bony union. In this series, the incidence of nonunion in acute odontoid fractures, managed by a variety of fixation methods, was $24 \%$ (11 of 45 ), or by fracture type was $30 \%$ for Type II and $17 \%$ for Type III injuries. These results compare favorably with the literature; the incidence of nonunion for Type II fractures ranges from 0-93\% averaging 40-50\%.,6,7 Greater than an $80 \%$ incidence of successful bony union has been achieved by external fixation methods for Type III odontoid fractures. $^{6,8-15}$ In our series, patients managed with halo immobilization had a lower nonunion rate $(24 \%)$ compared to patients managed with all other external devices (32\%). Four of six failed unions in patients treated in a halo vest were associated with Type II fractures; a previous review of primary halo bracing for Type II and Type III fractures demonstrated a $28 \%$ nonunion rate for Type II fractures compared to a $0 \%$ nonunion rate for Type III fractures. ${ }^{12}$ In an evaluation of halo vest versus other rigid external cervical orthoses, Polin et al $^{16}$ found a $100 \%$ fusion rate for Type III fractures regardless of treatment modality. Although the difference was not statistically significant, halo bracing favored improved healing over the Philadelphia collar in Type II fractures (74\% versus 53\%). Although our patient numbers are also too small to be certain, use of the halo vest was associated with a trend towards improved fusion rates compared to collars $(76 \%$ versus $69 \%)$. Within the limitations of a retrospective study, it is important to note that certain patients, either too frail or with other contraindications to halo immobilization, may have been placed in collars, predisposing them to nonunion (selection bias).

Most authors have found a direct relationship between age versus morbidity and mortality, and an inverse relationship 
between age versus rate of union. ${ }^{17-20}$ In this series, all 11 deaths were in patients aged 60 or greater. Five occurred in the acute setting while six occurred between 10 days and six weeks posttrauma. Neurological morbidity was distributed equally between old and young patients; of 12 spinal cord injuries, six occurred in patients over 65 years of age and the rest in younger patients. However, medical morbidity (primarily respiratory complications) was the major factor contributing to death in elderly patients (only two of 11 were related to the neurological deficit). Finally, the incidence of nonunion was significantly higher in the oldest age group (50\%) compared with the rest of the patient population $(16 \%)$.

The issue of fibrous nonunion in elderly patients with odontoid fractures has been addressed in the literature, with the suggestion that this may be a sufficient goal of treatment. ${ }^{21}$ In our study, one of eight elderly patients with fibrous nonunion was treated with posterior cervical fusion without complication; the remaining seven patients with a range of posterior subluxation of zero to $8 \mathrm{~mm}$ either remained in an external brace or had no further treatment, often because the surgical risk was deemed too high. In one to three years of follow-up available, none met with a catastrophic event.

Our results also suggest that primary operative intervention for acute Type II odontoid fractures, through an anterior approach where possible, may ultimately provide superior rates of bony union compared with external bracing. In this series, all acute Type II patients treated with anterior screw fixation (available for follow-up) went on to solid fusion, compared to eight of 37 acute Type II patients (30\%) who failed external bracing (Table 4). Posterior cervical fusion was similarly successful; the one case of loss of reduction, although suboptimal, was healed acceptably without further intervention required. These results are comparable to other published series in which satisfactory stabilization has been achieved in 80 to $100 \%$ of patients treated with posterior internal fixation, although rates of only $20 \%$ have also been described (in the absence of transarticular screws or postoperative halo bracing). ${ }^{17,22,23}$ In general, our results agree with others who suggest that surgical intervention should be entertained in a more aggressive fashion when other demographic factors predispose to nonunion, such as patient age, delay in diagnosis, direction and degree of subluxation, and complications during external fixation. ${ }^{8}$

Surgical procedures in this series of patients were biased to the oldest age group (28\%) compared to the youngest age group (9\%). Considering a nonunion rate in the elderly more than three times that observed in the younger groups (50\% vs. 16\%), and the fact that nonunion occurred exclusively in conservatively treated patients, the high fusion rates observed in the surgically treated (elderly) patients argues even more strongly in favor of this as a primary treatment modality.

\section{Conclusions}

In this retrospective review, halo immobilization for acute Type II and III odontoid fractures was associated with successful bone healing in $70 \%$ and $83 \%$ of patients respectively. A conservative approach consisting of halo bracing for 12 weeks is a traditional and effective method for the treatment of odontoid fractures in most patients, especially those of a younger age group. Halo fixation likely provides superior fusion rates compared to collar immobilization. With the introduction of newer surgical techniques, superior rates of bony union (perhaps approaching $100 \%$ ) even in elderly patients appear possible, with little, if any, additional morbidity. Although it is critical to acknowledge the retrospective nature of this study, including potential selection bias and limited follow-up, our results suggest that anterior surgical fixation may be preferential to external bracing as a primary treatment for acute Type II odontoid fractures. These observations lend themselves to further testing through a prospective randomized clinical trial.

\section{REFERENCES}

1. Amyes EW, Anderson FM. Fracture of the odontoid process: report of 63 cases. Arch Surg 1956; 72: 377-393.

2. Bohler J. Fractures of the odontoid process. J Trauma 1965;5: 386390.

3. Nachemson A. Fracture of the odontoid process of the axis. A clinical study based on 26 cases. Acta Orthop Scand 1960; 29 . 185-217.

4. Apfelbaum RI. Screw fixation of odontoid fractures. In: Wilkins RH, Rengachary SS (eds): Neurosurgery. New York: McGrawHill, 1996: 2965-2972.

5. Geisler FH, Cheng C, Poka A, et al. Anterior screw fixation of posteriorly displaced Type II odontoid fractures. Neurosurgery 1989; 25: 30-38.

6. Clark CR, White AAIII. Fractures of the dens. A multicenter study. J Bone Joint Surg Am 1985; 67-A: 1340-1348.

7. Lind B, Nordwall A, Sihlbom H. Odontoid fractures treated with halo vest. Spine 1987; 12: 173-177.

8. Dunn ME, Seljeskog EL. Experience in the management of odontoid process injuries: an analysis of 128 cases. Neurosurgery 1986; 18: 306-310.

9. Ekong CEU, Schwartz ML, Tator $\mathrm{CH}$, et al. Odontoid fracture: Management with early immobilization using the halo device. Neurosurgery 1981; 9: 631-637.

10. Fujii E, Kobayashi K, Hirabayashi K. Treatment in fractures of the odontoid process. Spine 1988; 13: 604-609.

11. Hadley MN, Browner CM, Sonntag VKH. Axis fractures: a comprehensive review of management and treatment in 107 cases. Neurosurgery 1985; 17: 281-290.

12. Hadley MN, Dickman CA, Browner CM, et al. Acute axis fractures: a review of 229 cases. J Neurosurg 1989; 71: 642-647.

13. Maiman DJ, Larson SJ. Management of odontoid fractures. Neurosurgery 1982;11:471-476.

14. Ryan MD, Taylor TKF. Odontoid fractures: a rational approach to treatment. J Bone Joint Surg Br 1982; 64-B: 416-421.

15. Wang GJ, Mabie KN, Whitehill R, et al. The nonsurgical management of odontoid fractures in adults. Spine 1984; 9: 229230.

16. Polin RS, Szabo T, Bogaev CA, et al. Nonoperative management of Types II and III odontoid fractures: the Philadelphia collar versus the halo vest. Neurosurgery 1996; 38: 450-457.

17. Appuzo MLJ, Heiden JS, Weiss MH, et al. Acute fractures of the odontoid process. An analysis of 45 cases. J Neurosurg 1978; 48 $85-91$

18. Johnson JC. The medical evaluation and management of the elderly surgical patient. J Am Geriatr Soc 1983; 31: 621-625.

19. Pepin JW, Bourne RB, Hawkins RJ. Odontoid fractures, with special reference to the elderly patient. Clin Orthop 1985; 193: 178-183.

20. Pringle RG. Fracture of the dens (odontoid process) of the axis. J Bone Joint Surg Br 1974; 56: 200-201(Proceedings).

21. Hanigan WC, Powell FC, Patrick BS, et al. Odontoid fractures in elderly patients. J Neurosurg 1993; 78: 32-35.

22. Anderson LD, D' Alonzo RT. Fracture of the odontoid process of the axis. J Bone Joint Surg Am 1974; 56: 1662-1674.

23. Fried LC. Atlanto axial fracture-dislocations. Failure of posterior C. 1 to C. 2 fusion. J Bone Joint Surg Br 1973; 55: 490-496. 